\title{
Parameters of the synthesized model of management of technosphere safety in the region
}

\author{
Vyacheslav Burlov ${ }^{1}$, Oleg Lepeshkin ${ }^{1}$, and Michael Lepeshkin ${ }^{1, *}$ \\ ${ }^{1}$ Peter the Great St. Petersburg Polytechnic University, 195251, Polytechnicheskaya Street, 29, St. \\ Petersburg, Russia
}

\begin{abstract}
The purpose of the study is to select and justify the conditions for guaranteed provision of the required level of technosphere security in the region based on the development of a synthesized model of integrated management. Method of research is the dynamic model based on the synthesis is formalized as a system of nonlinear differential equations. Three main system-forming indicators of social, economic, technical and technological systems, corresponding according to the law of preservation of integrity of object of V. G. Burlov. The solution is to construction phase portraits in MathCAD, which sufficiently fully and succinctly reflect the properties of differential equations under consideration, showing how it needs to change two measures that could be made to change the third.
\end{abstract}

\section{Introduction}

L. H. Kahn, J. A. Barondess write, that nations which have a higher gross national product, a more educated population, more social and political freedom providing the conditions for effective and active citizenship, and a more comprehensive financial system suffer fewer лоссы when extreme phenomena which occur provoke natural disasters [1]. There needs to be investment and natural disaster prevention subsidies as well as authorities and organizations who are directly responsible for preventing disasters, as this can significantly reduce the number of victims and extent of material damage. E. A. Blackstone, S. Hakim, B. Meehanb proposes a regional competitive governance and management of response and recovery from disasters [2].

In article [3] represents the analysis of using the possibilities of the scenario analysis methods and modelling in the process of solving the planning and management problems of measures to ensure the man-made safety of a wide range of potentially dangerous production and infrastructure facilities.

A. Madan, J. K. Routray write, that a number of factors such as awareness and perception, financial resources, technical resources, policy, institutional arrangements, leadership and human resources prevent effective and timely institutional preparedness and response to disasters [4]. In article [5] indicate that investing in disaster management capabilities is an interesting alternative, at significantly lower costs than pre-positioning

\footnotetext{
*Corresponding author: misha.lepeshckin@yandex.ru
} 
inventory. M. K. Lindell, C.S. Prater describes the ways in which hazard mitigation and emergency preparedness practices can limit the physical impacts and the ways in which community recovery resources and extra-community assistance can reduce social impacts [6].

Management of technosphere security (TS) of the region should be carried out on the basis of the results of modeling the processes of socio-economic development in the framework of the selected concept of management. In systems engineering, there are only two approaches to the development of systems (H. H. Goode, R. E. Machol):

1.Development of a system (model) based on analysis.

2.Development of a system (model) based on synthesis.

These two approaches correspond to solutions of direct and inverse tasks of research of operations.

Modeling of management on the basis of synthesis and the law of preservation of integrity of object is presented in works of V. G. Burlov [7-11], O. M. Lepeshkin [12, 13] and other.

\section{Methods}

\subsection{Mutual influence of Social, economic and technical-technological systems of the region}

Social, economic and technical-technological systems of the region have a mutual influence on each other. To build a model of management, it is necessary to determine the parameters and the necessary statistical data (Rosstat, Ministry of Energy of Russia). Consider the mutual influence systems of the region on the example of St. Petersburg. The social system St. Petersburg is represented in fig. 1 by the number of population and has a tendency to grow.

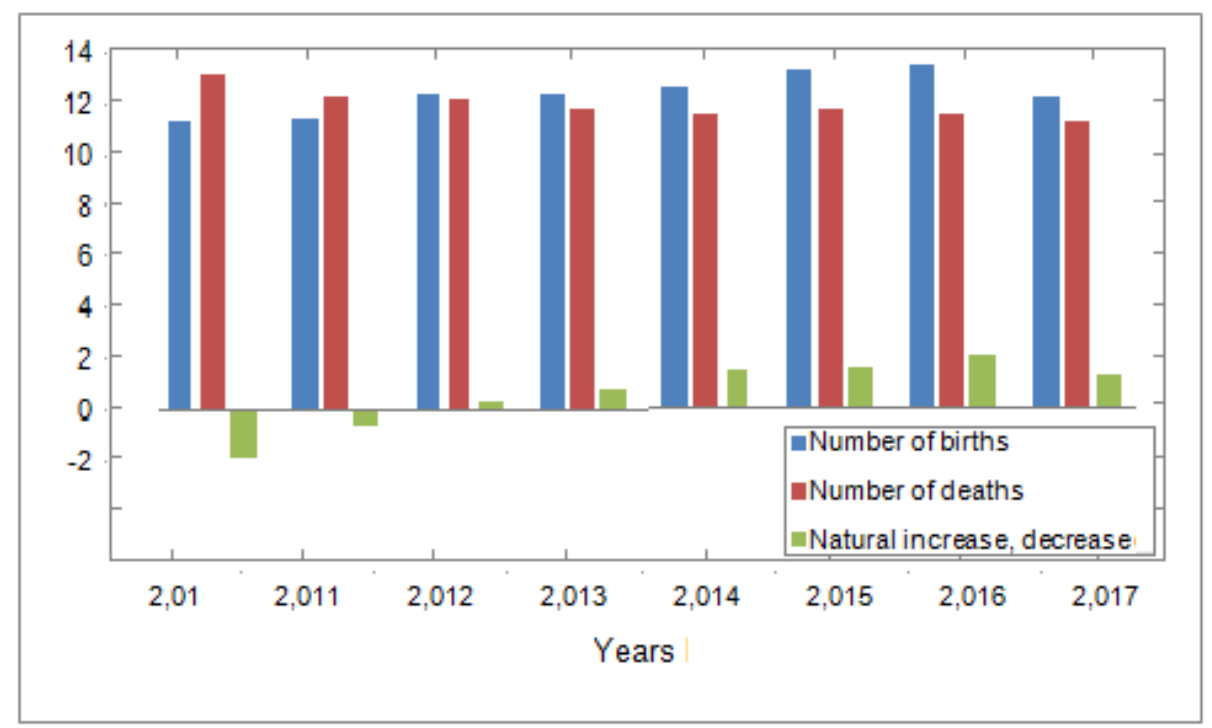

Fig. 1. Dynamics of the number of births, of deaths and natural increase, decrease (-) per 1000 population in St. Petersburg, people.

The mutual influence of the social and economic systems of the region is based on the mutual influence of the indicators of the number of jobs in the real economy and the 
indicators of the number of population. Fig. 2 shows a normalized graph of the dynamics and mutual influence of both indicators, which confirms their relationship.

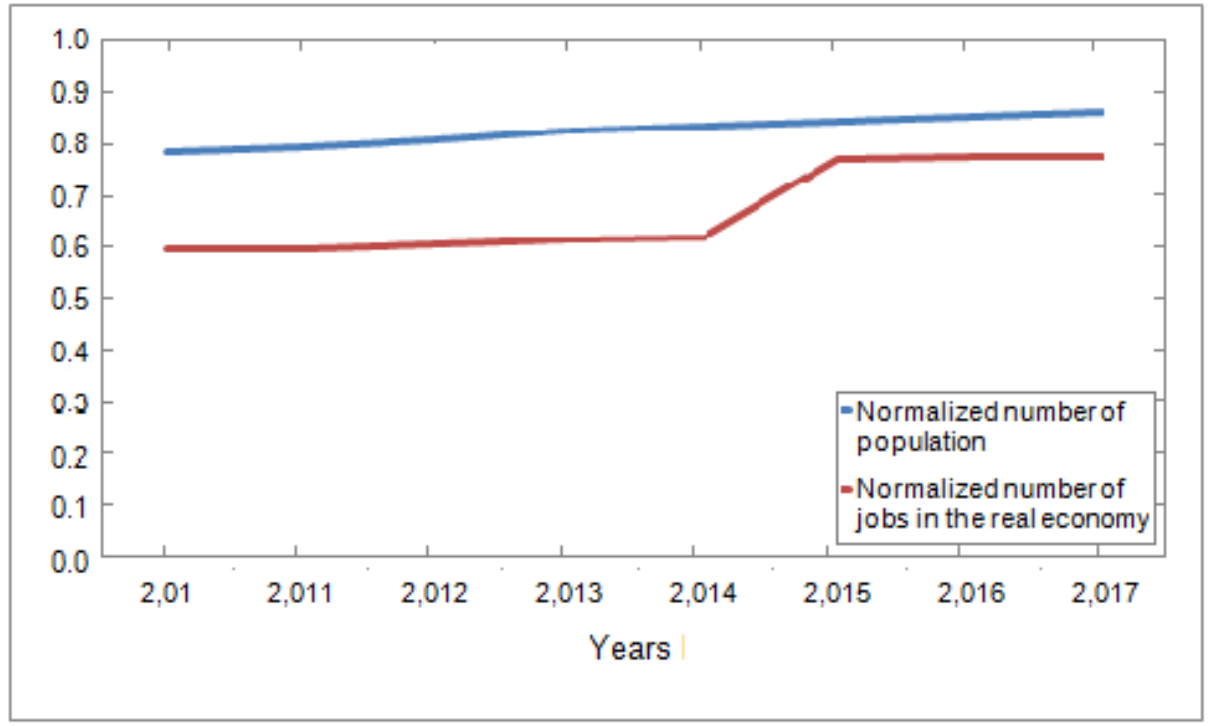

Fig. 2. Dependence of the indicators of the number of jobs in the real economy and the indicators of the number of population in St. Petersburg.

There is a dependence of the social system from technical-technological, in particular from the indicator of the energy supply in the region, where there is also an obvious regularity. Thus, the indicators of the number of population correlates with the indicator of the energy supply in the region, which is clearly illustrated in fig. 3.

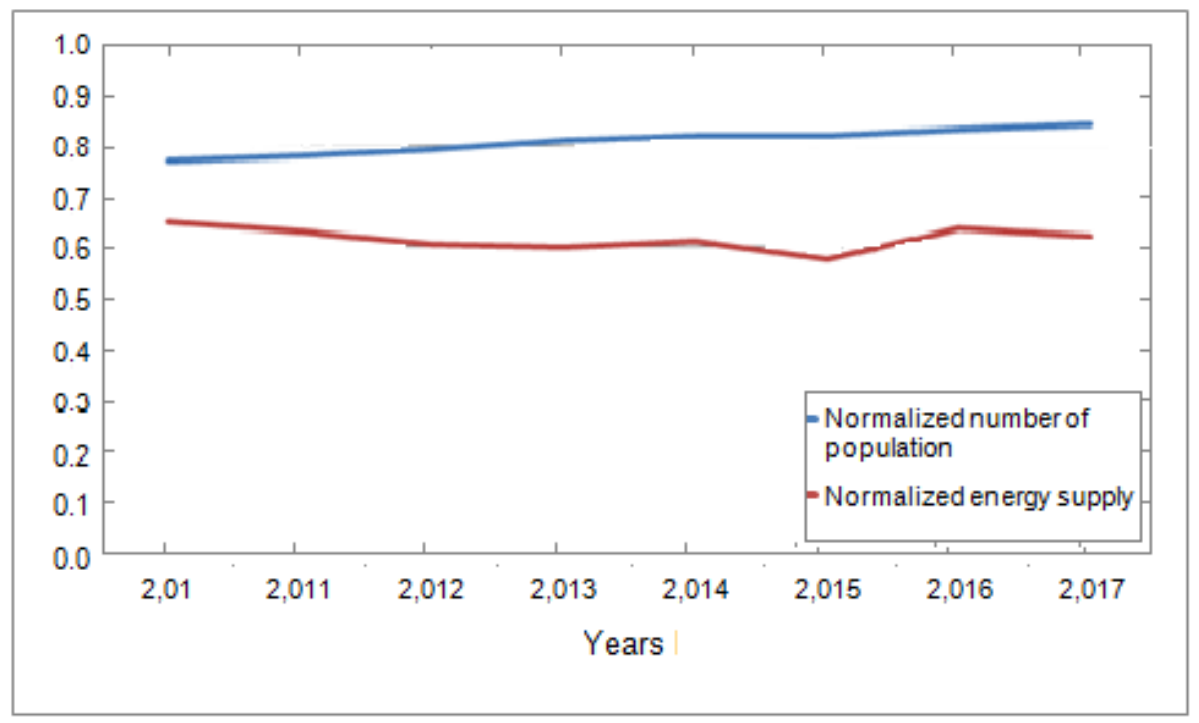

Fig. 3. Dependence of the number of population from the energy supply in St. Peterburg.

At the same time energy supply imposes a number of economic and social restrictions on the functioning of the region, i.e. to energy supply in the region the necessary staff and provision is also made, i.e. social, economic and technical-technological system of region 
are interrelated. Fig. 4 illustrates the dependence of the technical and technological system from the economic, which displays the normalized energy supply in the region and the normalized number of jobs in the real economy.

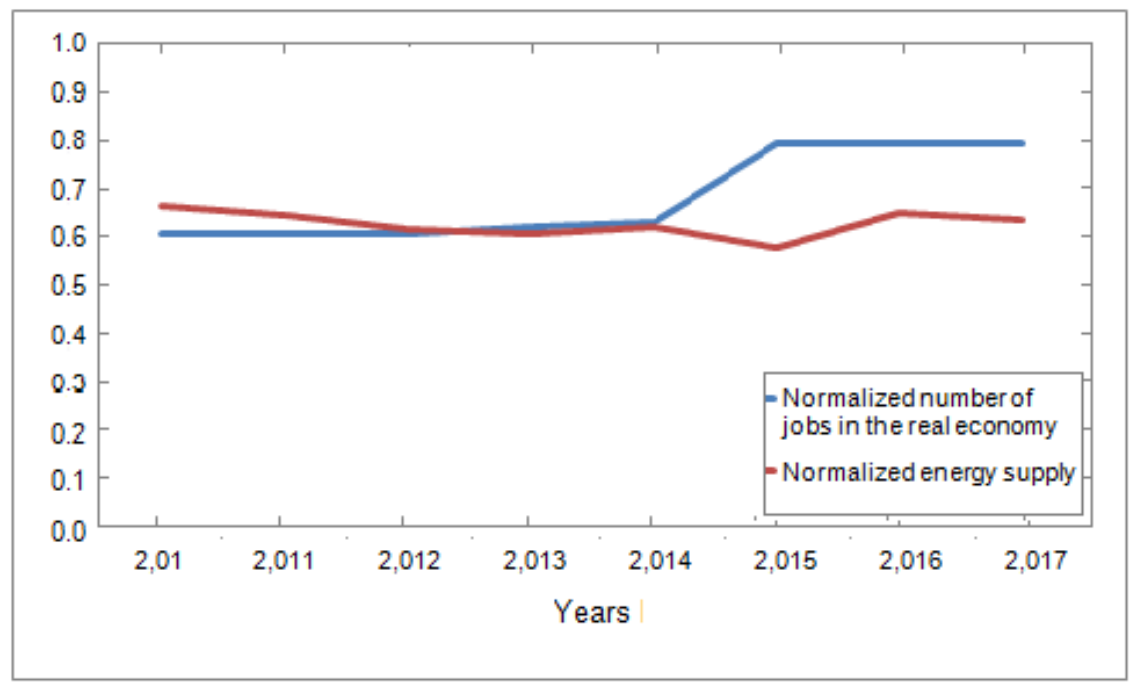

Fig. 4. Dependence of energy supply in the region from the normalized number of jobs in the real economy in St. Petersburg.

The analysis of social, economic and technical-technological systems of the region showed their dependence, respectively, in the development of the model is necessary to take into account these regularity.

\subsection{Synthesized model of management of TS of the region}

The dynamic model based on the synthesis is formalized as a system of nonlinear differential equations. One of the first descriptions of natural phenomena through a system of nonlinear differential equations was E.N. Lorenz [14-19]. Three main system-forming indicators of activity of the region, corresponding according to the law of preservation of integrity of object of V. G. Burlov [7-11;20] to three basic interconnected properties:

- indicator of social system of the region "x" (number of population);

- indicator of economic system of the region "y"(number of jobs in the real economy);

- indicator of technical and technological system of the region " $z$ " (energy supply in the region).

Formula (1) describes a system of differential equations of three systems of the region:

$$
\left\{\begin{array}{l}
\frac{\mathrm{dx}}{\mathrm{dt}}=a x-b x y+q x z ; a, b, q>0 ; \\
\frac{\mathrm{dy}}{\mathrm{dt}}=-p y+c x y+\gamma y z ; c, p, \gamma>0 ; \\
\frac{\mathrm{d} z}{\mathrm{dt}}=\mu z-\tau x z-\delta y z ; \delta, \mu, \tau>0 .
\end{array}\right.
$$

$x$, indicator of the number of population;

$y$, indicator of the number of jobs in the real economy;

$z$, indicator of the energy supply in the region;

$a$, the coefficient of demographic activity; 
$b$, the coefficient of negative attitude of people to childbearing;

$q$, coefficient of provision of energy in the region;

$c$, coefficient of people's interest in economic development;

$p$, coefficient of development of the real sector of the economy;

$\gamma$, coefficient of energy supply of workplaces;

$\mu$, coefficient of development of energy supply in the region;

$\tau$, coefficient of compliance of the population with energy supply;

$\delta$, coefficient of compliance of the economy's development with energy supply.

The backbone of the model is a system of differential equations and three dimensionless relative indicators: social, economic and technical-technological. Nine coefficients of the system of differential equations implement mechanisms of management for the processes of ensuring TS in the region.

Methods of nonlinear dynamics allow you to simulate fast, non-equilibrium processes (so-called phase transitions) in economic systems, related to the transition from one stable States in others. It is necessary to proceed to models aimed at describing non-equilibrium processes using the nonlinear dynamics apparatus.

In system of nonlinear differential equations need determine the coefficients of the backbone parameters $(x, y, z)$ obtained functional dependence of $l_{i}=f\left(K_{i 1}, K_{i 2}\right)$, which are described by smooth functions, so after their decomposition in a number Taylor obtained justification of ratios social, economic and technical-technological systems of the region through the definition of functional dependencies using common dependencies. This made it possible to identify the parameters of the model and are represented by formulas (2), (3), (4), (5), (6), (7), (8), (9) and (10):

$$
\begin{gathered}
\alpha=K_{r 0}-K_{r} y_{r}+K_{r 0}-K_{s} y_{s}+K_{m s 0}-K_{m s(y)} y_{m s}-K_{m s(z)} z_{m s} \\
b=-K_{r} \sigma_{r}+K_{s} \sigma_{s}+K_{m s(y)} \sigma_{m s(y)} ; \\
q=K_{m s(z)} \omega_{m s(z)} ; \\
p=K_{h t r m 0}-K_{h t r m} x_{h t r m o}+K_{d r m 0}-K_{d r m} z_{d r m} ; \\
c=-K_{h t r m} \sigma_{h t r m}-K_{d r m} \sigma_{d r m} ; \\
\gamma=-K_{d r m} \phi_{d r m} ; \\
\mu=K_{p r e} x_{p r e}-K_{p r e 0}+K_{p o e 0}+K_{p o e} y_{p o e} ; \\
\tau=K_{p r e} \phi_{p r e} ; \\
\delta=K_{p o e} \omega_{p o e} .
\end{gathered}
$$

To determine the above coefficients, an indexing system was developed and introduced, providing good visibility (table 1). 
Table 1. Indexing and description of parameters.

\begin{tabular}{|c|c|c|c|c|c|c|c|c|c|}
\hline \multirow[t]{2}{*}{$\begin{array}{l}\text { i-th } \\
\text { index }\end{array}$} & \multicolumn{3}{|c|}{$\begin{array}{c}\text { Parameter } \\
\text { denotes the } \\
\text { share }\end{array}$} & \multirow{2}{*}{$\begin{array}{c}\text { Primary } \\
\text { value the } \\
\text { coefficient }\end{array}$} & \multirow{2}{*}{$\begin{array}{c}\begin{array}{c}\text { Derivative } \\
\text { of } \\
\text { a function }\end{array} \\
\mathrm{K}_{\mathrm{i}} \\
\end{array}$} & \multicolumn{3}{|c|}{$\begin{array}{l}\text { Given } \\
\text { initial } \\
\text { values }\end{array}$} & \multirow[t]{2}{*}{$\begin{array}{l}\text { Value of the parameter with } \\
\text { i-th index }\end{array}$} \\
\hline & $\phi_{\mathrm{i}}$ & $\sigma_{\mathrm{i}}$ & $\omega_{\mathrm{i}}$ & & & $\mathrm{x}_{\mathrm{i}}$ & $\mathrm{y}_{\mathrm{i}}$ & $\mathrm{Zi}_{\mathrm{i}}$ & \\
\hline $\mathrm{r}$ & - & + & - & + & + & - & + & - & birth rate \\
\hline $\mathrm{s}$ & - & + & - & + & + & - & + & - & death rate \\
\hline $\mathrm{ms}$ & - & - & - & + & - & - & + & + & migration balance \\
\hline $\mathrm{ms}(\mathrm{y})$ & - & + & - & - & + & - & - & - & $\begin{array}{l}\text { migration balance due to } \\
\text { economic conditions }\end{array}$ \\
\hline $\mathrm{ms}(\mathrm{z})$ & - & - & + & - & + & - & - & - & $\begin{array}{l}\text { migration balance due to } \\
\text { energy supply }\end{array}$ \\
\hline htrm & - & + & - & - & + & - & + & - & high-technology jobs \\
\hline $\mathrm{drm}$ & - & + & - & + & + & - & + & - & other jobs \\
\hline pre & + & - & - & + & + & + & - & - & $\begin{array}{l}\text { produced fuel and energy } \\
\text { resources }\end{array}$ \\
\hline poe & - & - & + & + & + & - & - & + & $\begin{array}{l}\text { consumed fuel and energy } \\
\text { resources }\end{array}$ \\
\hline
\end{tabular}

\section{Results}

This system of nonlinear differential equations does not have a purely analytical solution, it is possible only by methods of numerical integration, for example, such as Adams, Euler, Runge-Kutta in MathCAD, which allow you to build solutions in the form of smooth curves. The obvious drawback for the practical application of the method is the difficulty of perception for analysis. Since the values may be the same or in absolute value be unsuitable for viewing. The solution is to construction phase portraits in MathCAD, which sufficiently fully and succinctly reflect the properties of the function under consideration.

Considering that three systems are considered, the most complete is the consideration of phase portraits in three-dimensional space, where the solution is represented as a corresponding spiral (fig. 5). 


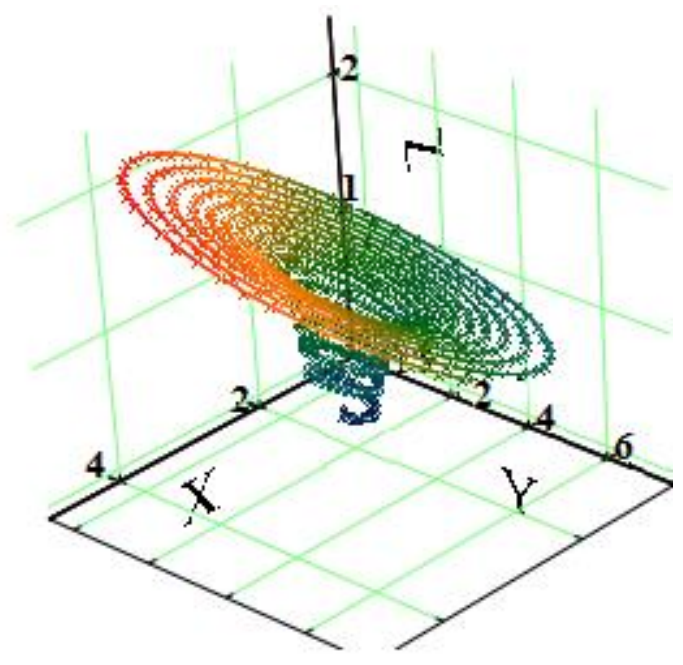

$(\mathrm{XX}, \mathrm{YY}, \mathrm{ZZ})$

Fig. 5. Phase portrait of the system in three-dimensional space.

The above synthesized model, formalized as a system of three differential equations, the solution and the analysis of which is proposed through numerical integration, which allows to evaluate the behavior of the main characteristics of the long time interval and to generate proposals for the adjustment of certain parameters.

\section{Discussion}

A point in a multidimensional phase space, characterizes the system, moving along a fairly stable trajectory, called an attractor, and with small perturbations returns back to the attractor. The system can change the attractor when exposed, exceeding the threshold value or with a small impact in critical point. A sharp change in the attractor is called bifurcation or disaster. Description of systems near bifurcation points allows us to study a real disaster.

The study of the model showed its sensitivity to parameters. If dynamic variables change, such as increasing production and consumption of fuel and energy resources, jobs, it is possible to move to a highly productive state of development of the region (an economic miracle), but there is a barrier in the phase space, and small changes in variables will not lead to its overcoming and the system will return to its previous state. For the transfer, the change must be greater than a certain critical value. After that, the system itself moves relatively quickly to another stationary state.

\section{Conclusions}

Thus, the backbone of the model is a system of differential equations and three dimensionless relative indicators: social, economic and technical-technological. Nine coefficients of the system of differential equations implement mechanisms of management for the processes of ensuring TS in the region. The methodological approach is developed, which allows by modeling the interaction of social, economic and technical-technological systems of the region to form the management of social and economic systems, determine the balance between the level of development of the technical and technological system and the state of the economic and social systems of the region and form recommendations. In 
both direct and indirect assessment of these factors based on known statistics for the region and solutions of this system we obtained the trajectories of the phase portrait, showing how it needs to change two measures that could be made to change the third. It becomes possible to program the state of one of the three baselines at a certain point in time. And not just to plan, but to form in the process of management, the components of the vector of which are the coefficients in the differential equation.

\section{References}

1. L.H. Kahn, J.A. Barondess, Urban Health 85 (6), 910-922 (2008) DOI: 10.1007/s11524-008-9310-y

2 E. Blackstone, S. Hakim, B. Meehanb, Evaluation and Program Planning 64, 57-68 (2017) DOI: 10.1016/j.evalprogplan.2017.05.014

3 V. Kulbaa, N. Bakhtadzea, O. Zaikinb, et al., Procedia Computer Science 112, 20662075 (2017) DOI: 10.1016/j.procs.2017.08.247

4 A. Madan, J. Routray, International Journal of Disaster Risk Reduction 14 (4), 545-555 (2015) DOI: 10.1016/j.ijdrr.2015.10.004

5 N. Kunz, G. Reiner, S. Golda, International Journal of Production Economics 157, 261-272 (2014) DOI: 10.1016/j.ijpe.2013.11.002

6 M.K. Lindell, C.S. Prater, Natural hazards review 4, 176-175 (2003) DOI: 10.1061/(ASCE)1527-6988(2003)4:4(176)

7 V. Burlov, A. Andreev, F. Gomazov, MATEC Web of Conferences 193, 1-8 (2018) DOI: $10.1051 /$ matecconf/201819302038

8 E. Istomin, V. Abramov, A. Fokicheva, et al., International Multidisciplinary Scientific GeoConference Surveying Geology and Mining Ecology Management, SGEM, Albena, Bulgaria (2017) DOI: 10.5593/sgem2017/21/S08.127

9 E.P. Istomin, V.M. Abramov, V. G. Burlov, et al., 17th International Multidisciplinary Scientific GeoConference 17, 859-866, Sofia (2017) DOI: 10.5593/sgem2017/21/S08.109

10 E.P. Istomin, V.G. Burlov, V.M. Abramov, et al., International Multidisciplinary Scientific GeoConference: SGEM, Surveying Geology \& Mining Ecology Management 19, ed.5.3, 139-145, Sofia (2019) DOI:10.5593/sgem2019/5.3/S21.018

11 E.P. Istomin, V.M. Abramov, O.M. Lepeshkin, et al., International Multidisciplinary Scientific GeoConference: SGEM, Surveying Geology \& Mining Ecology Management 19, ed. 5.3, 953-959, Sofia (2019) DOI: 10.5593/sgem2019/5.3/S21.120

12 V. Burlov, O. Lepeshkin, Transportation Research Procedia 20, 94-96 (2017) DOI: 10.1016/j.trpro.2017.01.021

13 V.G. Burlov, O.M. Lepeshkin, M.O. Lepeshkin, and F.A. Gomazov, Conference Series: Materials Science and Engineering 618, 012088 (2019) DOI: 10.1088/1757899X/618/1/012088

14 E.N. Lorenz, Annals of the New York Academy of Sciences 357 (1), 282 - 291 (2006) DOI: $10.1111 /$ j.1749-6632.1980.tb29693.x

15 E.N. Lorenz, Tellus 16, 1-11 (2010) DOI: 10.1111/j.2153-3490.1964.tb00136.x

16 E.N. Lorenz, SIAM Journal on Applied Mathematics 32 (1) (1977) DOI: $10.1137 / 0132005$

17 E.N. Lorenz, Annals of the New York Academy of Sciences 163 (1), 62 - 68 (2006) DOI: $10.1111 /$ j.1749-6632.1969.tb13033.x 
18 E.N. Lorenz, Tellus $36 \quad$ A(2), 98 - $110 \quad$ (2010) DOI: 10.1111/j.16000870.1984.tb00230.x

19 N.A. Magnitskii, S.V. Sidorov, Differential Equations 37(11), 1568-1579 (2001) DOI: 10.1023/A:1017964715240

20 A.V. Andreev, V.G. Burlov, et al., International Science and Technology Conference "EastConf", 1-5, Vladivostok (2019) DOI: 10.1109/EastConf.2019.8725428 